\title{
The Relationship Between Monetary Base and Money: How Close?
}

\author{
ALBERT E. BURGER
}

I

AATELY, there has been considerable discussion about setting targets for the growth rate of money. However, of those proposing such targets for monetary growth, none has stated the probability that the actual growth rate of money will fall within the bounds they have suggested. Clearly, the Federal Reserve camot guarantee with 100 percent certainty that it will achieve any specific growth rate of money, and Congress should not expect the Federal Reserve to do so. There always exists a probability greater than zero that the growth rate of money will exceed or fall short of its targeted rate by some amount. If investors and businessmen are going to use publicly announced targets for the growth rate of money in their investment decisions, it would be helpful to them to be able to determine the probability that such a growth rate will be achieved.

The operational procedure the Federal Reserve uses to achieve a monetary growth rate is crucial in determining the probability that the announced growth rate for money will be achieved. Using historical evidence, this article develops confidence intervals for the growth rate of money associated with two procedures whereby the Federal Reserve would use its control over the monetary base as the means to achieve a growth path for money. This type of analysis helps answer questions such as the following: if the Federal Reserve announced that it desired the growth rate of the money stock to be 6 percent over a specified future period, say the next twelve months, then based on the historical evidence, what would be the probability that the growth rate of money would fall within some bounds of, say, 5 to 7.5 percent?

The first procedure is one in which the Federal Open Market Committee (FOMC) would direct the Trading Desk to maintain the growth of the monetary base at the same rate as its desired growth rate for money. For example, if the FOMC decided it wanted the money stock to grow at a 6 percent rate over the next twelve months, it would direct the Desk to have the monetary base grow at a 6 percent rate over the next twelve months. The second procedure is one in which the relationship between the monetary base and money (the money multiplier) would be "predicted" each month. Using these predictions of the multiplier, the Desk would supply the amount of monetary base necessary to hit their target value for money.

The Federal Open Market Committee is frequently interested in evaluating the effects of its actions over the next year where the "year" may begin in the month of the FOMC meeting, not necessarily in January. Therefore, throughout this analysis consecutive moving time intervals are used. This permits the analysis to be developed with a large number of observations. For example, there are 216 observations on rates of change of the base and money over consecutive moving twenty-four month intervals included in the sample period spanning the twenty years from 1954 through 1973..$^{1}$ The analysis begins with month-tomonth observations of the difference between the growth rates of monetary base and money, and then the time interval is progressively lengthened to consecutive twenty-four month intervals. The same procedure is then repeated using quarterly data, where the longest time period considered is eight quarters.

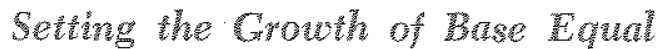 to the Besired Crowth of Money}

The mean (average) difference between the growth rates of the monetary base and the money stock provides evidence as to how close the growth rates of these two aggregates have been, on average,

1The results were not significantly different if the sample period was altered. For exarnple, essentially the same results held for all length time intervals within a sample period 1954-63 and within a sample period 1964-73, and these results were essentially the same as those for the longer sample period 1954-73. 


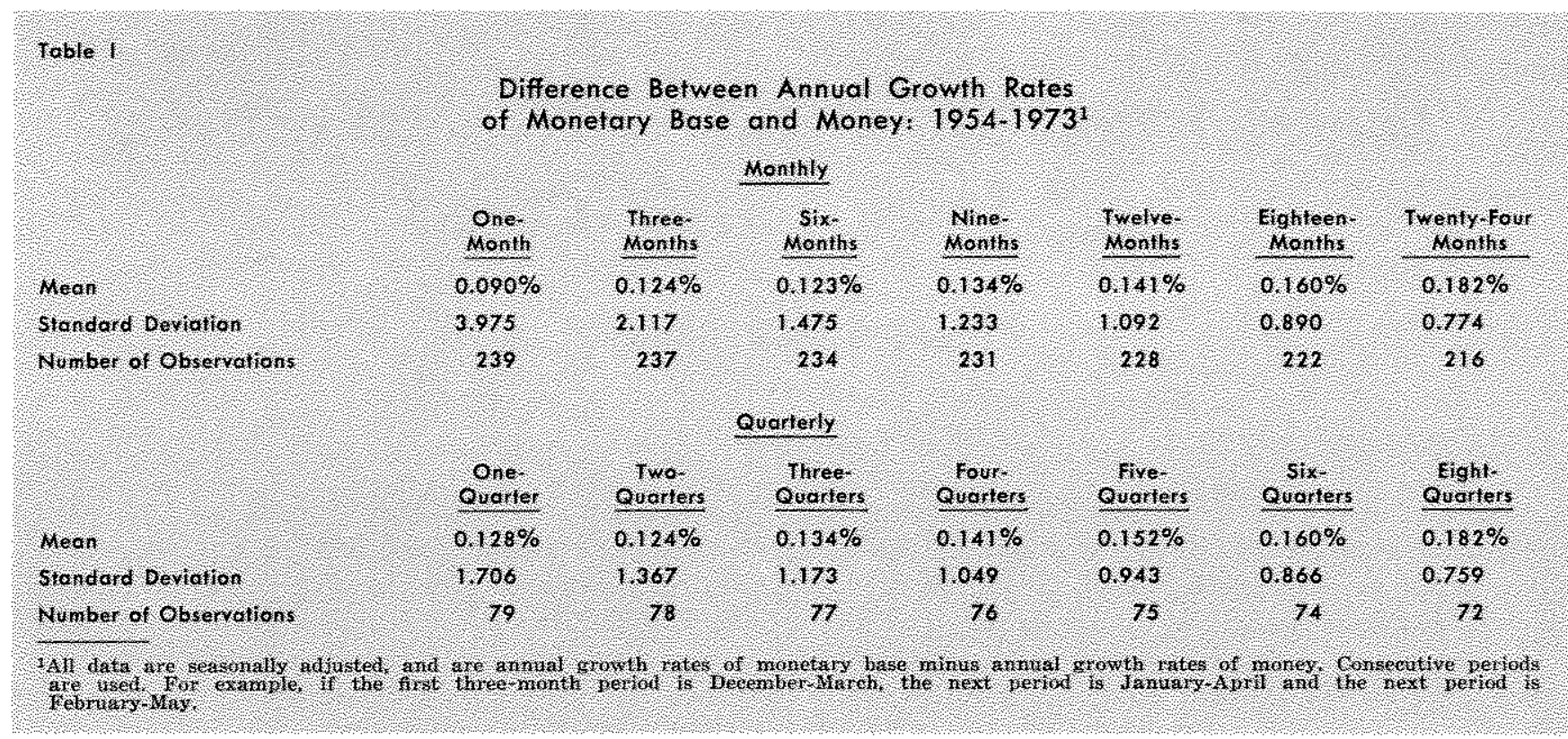

over different length time intervals. However, even if the mean difference is very small, there may be considerable variation about this mean. The standard deviation of these differences permits the establishment of confidence intervals on the difference between the growth rates. In this manner, conditional statements can be made about the probability that the growth rate of money will diverge from the growth rate of the base for a time period of specified length."

Some financial analysts prefer to use month-tomonth comparisons, while others prefer quarter-toquarter comparisons. Therefore, Table I presents the mean and standard deviation of the difference between the growth rates of the seasonally adjusted monetary base and money on monthly and quarterly bases, respectively. For all length time periods the mean of the difference is very small, showing that, regardless of the length of the time period, the growth of the money stock was approximately the same, on average, as the growth of the monetary base.

However, there are substantial differences with respect to the variation about this mean as the length of the time period is altered. In general, the longer the time interval, the smaller is the variation around the mean. For example, the monthly data show a standard deviation of 4 percentage points for a onemonth interval, then the standard deviation steadily decreases as the time interval lengthens, reaching

These probability statements are conditioned upon the assumption that future observations are drawn from the same population as the sample observations. about 0.75 percentage point for twenty-four month intervals. " The quarterly data show a similar pattern, though less pronounced than the monthly data. The quarterly data are an average of three months data, hence a considerable part of the very short-run variation between the relative growth rates of money and base is reduced.

The standard deviation can be used to make conditional probability statements about the difference between growth rates of base and money for specified time periods. For example, as shown in Table I, the mean of the difference between the growth rates of base and money over all consecutive twelve-month periods from 1954 through 1973 is 0.141 percentage point, and the standard deviation is 1.092 percentage points. Therefore, based on the historical evidence, one would expect that 95 percent of the observations on the growth rate of money over all twelve-month periods would be between about +2.3 percentage points and -2 percentage points of the growth of the base.

3The term "percentage points" is used to denote differences between growth rates which are expressed in percent per annum. For example, if the growth rate of base is 6 percent and the growth rate of money is 5 percent, then the difference between the growth rates of base and money is one percentage point.

Assuming these observations are drawn from a population where the observations are normally distributed, about 68 percent of the observations lie within plus or minus one standard deviation of the mean, and about 95 percent of the observations lie within plus or minus two standard deviations of the mean. The frequency distribution of the observations was examined and Chi-square tests were performed. These tests supported the assumption that the observations were drawn from a nomally distributed popilation. 
Since the mean of the differences between the growth rates of base and money is about zero, the most likely result over a twelve-month period is that the growth of money would be approximately the same as the growth of the monetary base. By methodological convention one would say that, based on the historical evidence, it would be very unlikely (in the sense of having occurred only 5 percent of the time) that the growth rate of money would diverge from the growth rate of the monetary base by more than about \pm 2 percentage points over any given twelvemonth period.

These results in Table $\mathrm{I}$ indicate the following conclusions:

(1) It is not unlikely that over a short time period the growth of the monetary base will be substantially different from the growth rate of the money stock.

(2) As the time period lengthens, the deviations between the growth of the money stock and the monetary base are reduced significantly. For example, lengthening the comparison interval from month-to-month growth rates to a sixmonth interval reduces the standard deviation from 4 percentage points to 1.5 percentage points, a reduction of over 60 percent.

These conclusions have practical implications for a situation in which the FOMC would decide that it wanted money to grow at a 6 percent rate over the next twelve months, and then instucted the Trading Desk to operate so as to achieve a 6 percent rate of growth for the monetary base. It would not be unlikely that for the first few months the growth rate of money might be significantly different than 6 percent, even if the growth rate of the base was maintained at a 6 percent rate.

The FOMC shonld not be "alarmed" at this result, and should not drastically alter its target growth rate for the monetary base as a result of this deviation. Historical evidence suggests that the probability of achieving a 6 percent growth rate of money by a maintained policy of controlling the growth rate of the base at 6 percent increases substantially as the time period lengthens. Historical evidence indicates that with a 6 percent growth rate of the monetary base over a twelve-month period there would be a 95 percent probability that the growth of money over this period would be in the range of 4 to 8 percent.

\section{An Alternative Approach to Controlling Money}

The above procedure yields, on average, fairly satisfactory results. However, at certain times, diver- gences between the growth rates of monetary base and money have been great enough and lasted long enough so that the changed growth rate of money had an undesired influence on economic activity. The period from about mid-1974 into early 1975 was an example of this situation.

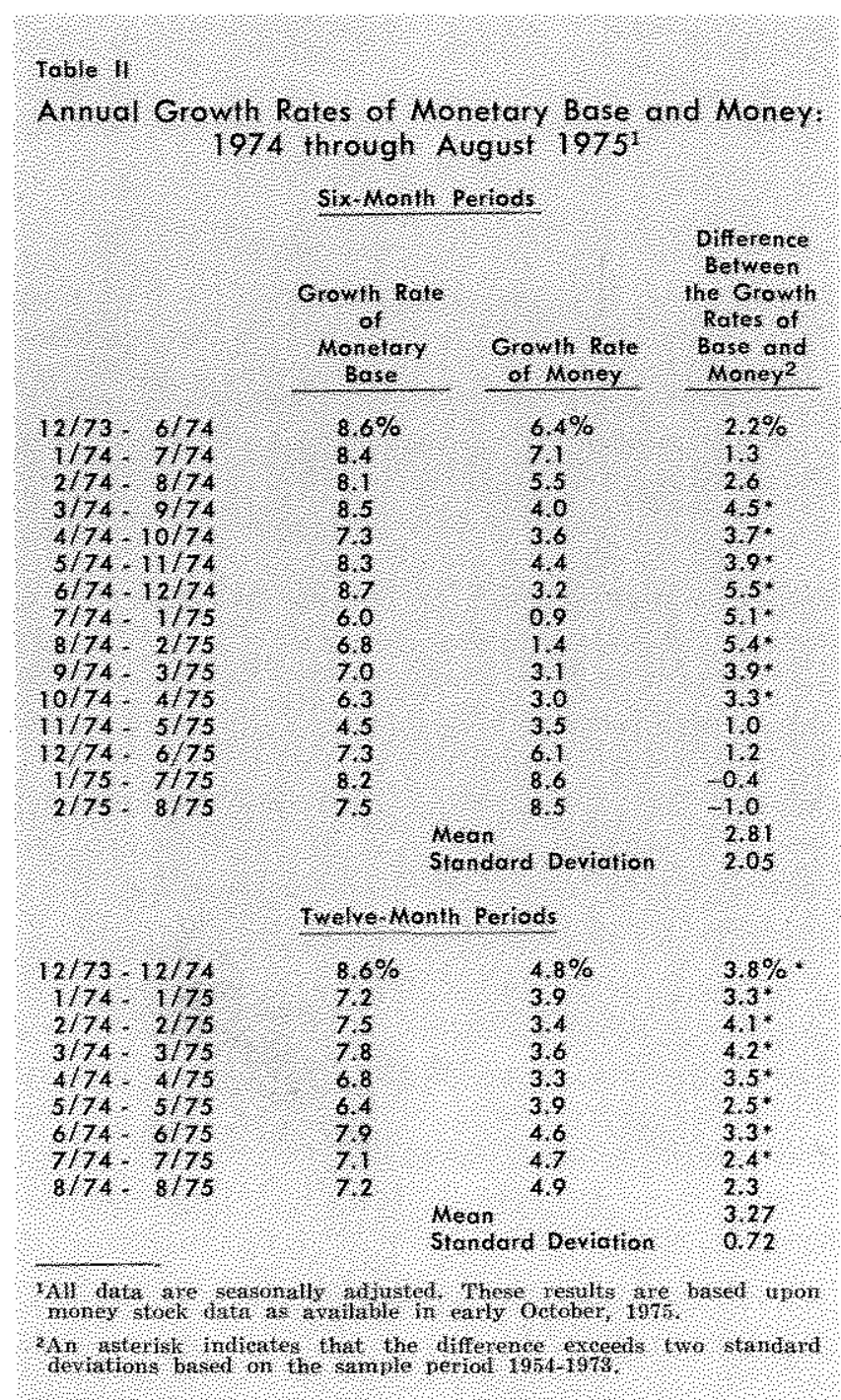

Beginning about mid-1974 and carrying into early 1975 , the divergence between the growth rates of monetary base and money was unusually large by the historical standard of the period 1954-73.5 For many of the consecutive six- and twelve-month periods reported in Table II the divergences exceed two stand. ard deviations. For example from February 1974 to February 1975 the monetary base tose 7.5 percent but the money stock increased only 3.4 percent. "See Albert E. Butger, "Explanation of the Growth of the
Money Stock: 1974-Early 1975," this Review (September 1975), pp. 5-10. 


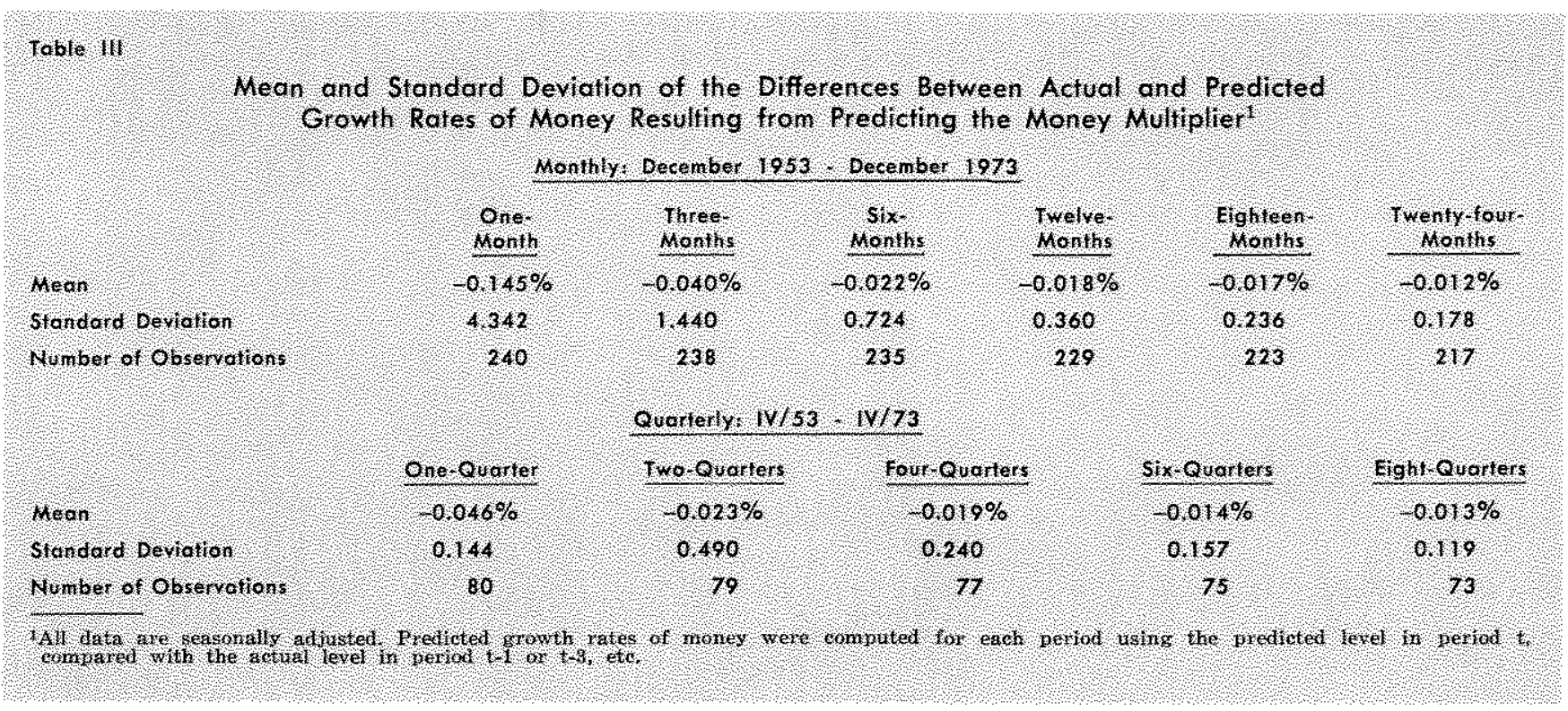

Therefore, an alternative approach in which the monetary base remains the keystone for control of money is suggested. In this procedure the money stock is expressed as $M=m B$, where " $m$ " denotes the money multiplier and " $\mathrm{B}$ " denotes the monetary base. The multiplier summarizes all those factors not included in the monetary base that influence the money stock. In other words, divergences between the growth rates of money and base reflect fluctuations in the money multiplier. ${ }^{*}$

Are periodic variations in the money multiplier predictable enough to allow for offsetting actions by the Federal Reserve? Could the Federal Reserve improve its control over money by predicting the multiplier and then, using these predictions, supply the amount of monetary base consistent with its targeted value for the money stock?

To help answer this question, a procedure was de veloped for predicting the money multiplier using only that information available to the Federal Reserve at the time the predictions were made. Each month the money multiplier was predicted and, given this prediction, the money stock likely to result from a given amount of base was determined. The level of the money stock the FOMC desired to achieve was assumed to be equal to the product of the predicted money multiplier and the actual level of the monetary base.

Predicted growth rates of money were computed by comparing the actual level of the money stock in

if the maltiplier was constant, then the elasticity of money with respect to the base would be equal to one. the initial period with the predicted level in the final period. For example, the predicted growth rate of money from December to January was computed by comparing the actual level of the money stock in December with the level of the money stock predicted for January using data through December in the prediction. To compute the predicted growth rate for money over the six-month period from December to June, the actual level of money for December was used. The predicted level for June was computed using data through May. It is assumed that for each month from December through Jume the Federal Reserve was predicting a money multiplier and then supplying the amount of base consistent with its target level for the money stock. In some months this procedure resulted in money being above target, and some months below target. The comparison of the six month predicted growth rate of money and the actual growth rate of money indicates how far off target the Federal Reserve would be after six months. ${ }^{7}$

This procedure for controlling the growth of money was simulated for the $1954-73$ period. The mean and standard deviation of the differences between predicted and actual growth rates of money are given in Table III. Comparing these results with those reported in Table $I$ it can be seen that for very short periods, such as a month, no improvement results over assuming that the growth rate of money and base will

7For a more complete explanation of this procedure, see Albert E. Burger, "Money Stock Control," Controlling Monetary Aggregates II: The Implementation, Federal Reserve Bank of Boston, pp. 33-55. The procedure used in this paper differs from the procedure explained in "Money Stock Control" only in that seasonally adjusted data have been used in this article. 
be equal. The standard deviation is large for onemonth periods in both procedures.

However, for periods longer than a month, there is a substantial improvement resulting from using a procedure that requires predicting the money multiplier. For six-month periods the standard deviation between actual and predicted growth rates of money falls to about 0.75 percentage point, compared to 1.5 percentage points under the first procedure whereby the growth of base and money are assumed to be equal (Table I). For one-year periods a further substantial improvement results from predicting the money multiplier as the standard deviation between the actual and the predicted growth rates of money is reduced to 0.4 percentage point.

Suppose the Federal Reserve had used the procedure outlined above in 1974 and early 1975 to predict the money multiplier, and had used the predictions to determine the likely growth path of money resulting from the actual path of the monetary base. Would these predictions of the multiplier have enabled the Federal Reserve to more accurately predict the effects of its actions on the growth rate of money?

Table IV presents the results of predicting the money multiplier and generating predicted growth rates of money throughout 1974 and into mid-1975 in the manner discussed at the start of this section. Comparing these results with Table II, it appears that predicting the money multiplier substantially reduces the size of the errors, especially for the period spanning mid-1974 into early 1975 when there were wide divergences between the growth rates of base and money. Generally, the difference between the actual growth rate of money and the growth rate of money associated with predictions of the multiplier are quite small. The mean difference between actual and predicted growth rates of money resulting from forecasting the money multiplier is about 0.25 percentage point for both consecutive six- and twelve-month periods from mid-1974 through August 1975.

\section{Conclusions}

Any statement about a proposed target for monetary growth should be accompanied by a statement about the likelihood or probability that the growth of money will fall within some range about the target rate. Such probability statements depend crucially upon the procedure by which the Federal Reserve attempts to achieve a growth path of money and upon the time period over which it is to be achieved. Un-

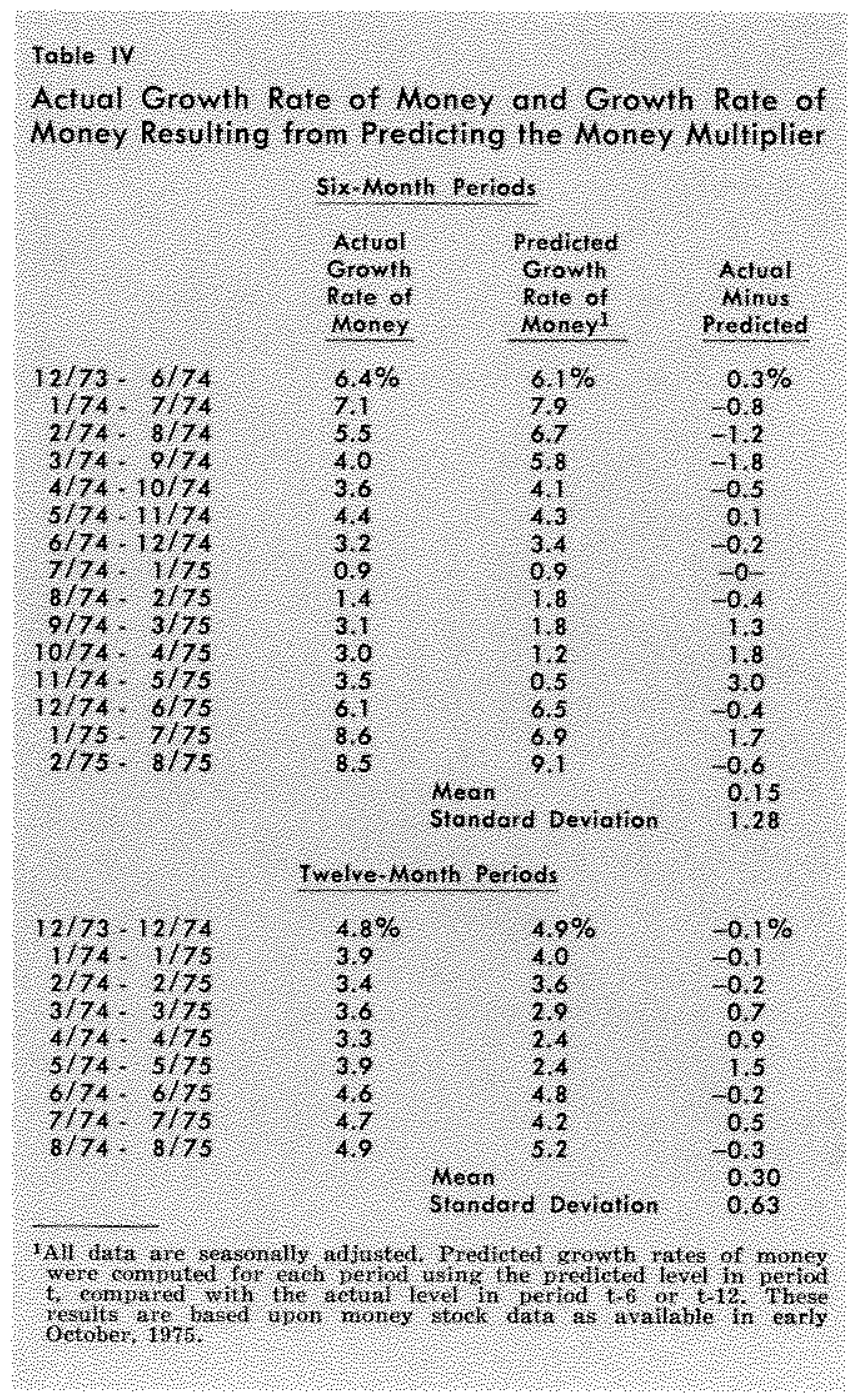

less the method by which money is to be controlled is made explicit, there is no way of determining the probability that the growth rate of money could be held, say, within a 5 to 7.5 percent range. All anyone knows is that the probability is greater than zero and less than one.

Historical evidence of the twenty years from 1954 throngh 1973 shows that the growth rate of money has been, on average, about the same as the growth rate of the monetary base for all length time periods. Therefore, one method for controlling the growth of the money stock would be to set the growth rate of the monetary base approximately equal to the desired growth rate of money. However, the evidence also shows that the length of the time period considered makes a major difference as to the tightness of this average relationship. Over short periods it has not been uncommon for the growth rate of money to diverge substantially from the growth rate of the 
monetary base. Over longer periods of time, such as twelve mouths, however, the growth of money has adjusted to the growth of the base.

The empirical evidence supports the view that the growth rate of money would adjust to the growth rate of the monetary base if the Federal Reserve would adhere to the following set of guidelines,

(1) decide upon a growth path for money over a twelve-month period;

(2) control the growth of the monetary base at the same rate as the policy determined growth of money;

(3) not react to monthly errors in the growth of money - in other words, hold the growth of the base constant.

Over a twelve-month period, it would be an "unlikely" event for the growth rates of money and base to diverge by more than \pm 2 percentage points. Therefore, if the Federal Reserve chose a 6 percent growth rate for money over a twelve-month period, there would be a 95 percent probability that it would be in the range of 4 to 8 percent.

The empirical evidence suggests that, the Federal Reserve could reduce the margin of error in achieving its desired growth rate of money if it would adopt an altemative procedure for controlling money whereby:

(1) the FOMC first decided upon a growth rate of money over a twelvemonth period and then,

(2) each month the money multiplier was predicted and the amount of base was supplied that was consistent with the desired level of money stock.

For example, the experiment discussed in the last section of this paper indicated that the standard deviation between actual and desired growth rates of money for twelye-month periods would be reduced to about 0.4 percentage point Hence, it would be "unlikely" for the divergence between the desired and actual growth rates of money to exceed 0.8 percentage point with this procedure, compared to 2 percentage points under a procedure of setting the growth rate of the base equal to the desired growth rate of money. Using this latter procedure, if the Federal Reserve decided upon a 6 percent growth for money over the next twelve months, the Federal Reserve could state that there would be a 95 percent probability that the growth of money would fall in the range of about 5 to 7 percent.

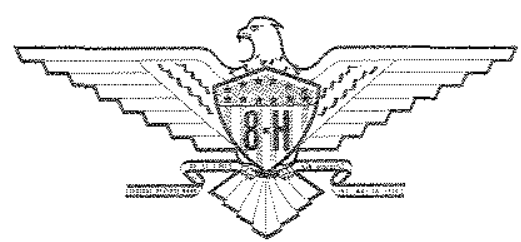

